\title{
El cine de Krzysztof Kieslowski: la Perfección y el Azar
}

\section{The Cinema of Krzysztof Kieslowski: Perfection and Chance}

Jesús Solera: Universidad Autónoma de Madrid (España) jesus.solera@yahoo.es

\section{CURRÍCULUM VITAE}

Profesor de la Universidad Autónoma de Madrid (España). Es licenciado en Bioquímica y Medicina. Sus trabajos han sido publicados en más de una decena de revistas especializadas.

\section{RESUMEN}

Se analiza brevemente lo esencial de la obra cinematográfica del director polaco Krzystof Kieslowski (Varsovia, 1941-1996) y de Krzystof Pisiewick (Varsovia, 1945) su guionista. Básicamente son dos vectores (paradójicamente opuestos) los que la fundamentan: la Perfección y el Azar. Ambos actúan sobre la vida del ciudadano del mundo occidental: a la presión del primero, Kieslowski ofrece la abertura del segundo. Este es su análisis de la sociedad europea y, lo que es más importante, así lo traslada a su lenguaje cinematográfico. De esta forma, demostrando su inmensa personalidad, se aleja de las tendencias frívolas y banalizadoras del cine en la posmodernidad, que ha esterilizado y mecanizado el lenguaje cinematográfico. Desde su soledad intelectual y artística nos dejó una obra clave para la cinematografía mundial. Una obra que nos ayuda a entendernos a nosotros mismos. 


\title{
PALABRAS CLAVE
}

Perfección - Azar - Posmodernidad - Lenguaje - Mecanización

\begin{abstract}
TThis article looks into the essence of the work of Polish director Krzystof Kieslowski (Warsaw, 1941-1996) and his scriptwriter Krzystof Pisiewick (Warsaw, 1945). Their cinematography rests on two pillars, which paradoxically are confronted: Perfection and Chance or random events. Both pillars have a bearing on common lives in the Western world. The pressure exerted on man by the first pillar is countered by the lightness of the second one. Kieslowski's cinematography reflects his own views on European society and this very approach separates him from the frivolity and banality of postmodern cinema, characterized by the sterility and mechanization of cinematographic language. Kieslowski’s solitary confinement and artistic isolation has given us a product that is a key element in cinematography as we know it. Kieslowski and Pisiewick created a work that helps us understand our own very self.
\end{abstract}

\section{KEY WORDS}

Perfection - Chance - Postmodernism - Language - Mechanisation

\section{TEXTO}

Para muchos críticos y profesionales del medio la decadencia del cine empezó a fraguarse a finales de los setenta y principios de los ochenta, todavía entonces daban los últimos coletazos algunos de los grandes directores de otra época antes de que la 
edad o el mercado les impidiera hacer más películas. Sin embargo en la convulsa Polonia estaba surgiendo en la sombra el que sería uno de los últimos grandes (algo parecido ocurría en Portugal con el viejo Oliveira), y que se descubría fundamentalmente a través de la televisión de su país. Era Krzystof Kieslowski (Varsovia, 1941 - 1996) y su inseparable guionista Krzystof Pisiewick (Varsovia, 1945). Mientras en la Europa libre la posmodernidad marcaba la tendencia hacia la frivolidad, mecanizando el lenguaje cinematográfico y firmando la sentencia de muerte del cine, ambos mantenían la llama encendida y apostaban, tras el telón, fuera del libre mercado capitalista, por un cine que indagaba en lo más íntimo del ser humano en relación a la sociedad en la que vive, en la línea de la más pura tradición cinematográfica centroeuropea.

El impacto de Kieslowski en el gran público tardaría en llegar a España, de hecho no sería popularmente conocido hasta la famosa Trilogía: Blanco, Azul y Rojo 1993-94. Sin embargo ya mucho antes en el resto de Europa Decálogo 1988 había dejado su huella, e indicaba que estábamos ante dos grandes cineastas. Maestros hasta tal punto que uno de los capítulos, No amarás de 55 minutos (más tarde también No matarás), fue convertido en largometraje (90 minutos aprox.) y distribuido en las salas comerciales de Europa. Los dos (capítulo y largometraje) funcionan a la perfección, como un reloj de precisión; algo que será característico del cine del director polaco. Y esto que parece una banalidad es sin embargo lo más difícil; en la versión corta no falta un plano, en la larga no sobra tampoco ninguno: imposible de creer pero cierto. Es la 'maquinaria perfecta' de Kieslowski y Pisiewick. Pero lo que es pura técnica y austeridad narrativa pasa a ser magia: la que desprenden sus películas; y lo que es una ajustadísima mecánica se convierte en el misterio mundano, diario, común - que envuelve a sus personajes. Pocas veces un cine tan técnico y tan perfectamente ensamblado, pocas veces la fría perfección ha transmitido tanto - ¡qué diferencia con el cine de Louis Malle! -. El cine de otros directores de ese nivel emana sentimiento (Mizoguchi), humanidad (Rossellini), 
sencillez (Truffaut, Kiarostami), desasosiego (Angelopoulos)...; todos ellos se comprende que, como espectadores, nos lleguen directamente porque yerran, ellos, sus películas y sus personajes; porque son claramente imperfectos como lo somos nosotros, sin embargo Kieslowski crea la perfección, crea con perfección que no es humana pero sus personajes lo son y sus películas también. ¿Cómo entenderlo? Es más, ¿cómo explicarlo?

El preciso ensamblaje de sus películas (personajes y estructura narrativa, planos y ritmo, tipos y ambiente...) es, trasladado al lenguaje cinematográfico, la seguridad y estabilidad de la sociedad actual que nos envuelve; sin embargo tras ella palpita el ser humano, pequeño, perdido pero presente bajo este paraguas sobrecogedor de protección que, sin embargo, empuja sus sentimientos hacia la marginalidad desvalorizándolos y vaciando así su existencia. (Así vive el amor y el sexo la protagonista de No amarás: banalizado, sin valor; sin embargo el adolescente todavía lo siente de otra manera aunque, incapaz de hacerlo suyo, lo vive a través de la técnica y de la distancia, a través de la fría óptica del telescopio -metáfora que cada espectador puede y debe interpretar a su manera-). Esto es lo que refleja de forma insuperable, como ningún otro director, el cine de Kieslowski; no sólo en el contenido sino, también y sobre todo, formalmente, muy lejos del habitual y monótono plano contra plano en primer plano de la gran mayoría de las películas actuales: no importa el tema, no importa quien las firma. Kieslowski no se divierte con sus personajes, ni hace que el espectador se los tome a broma como otros directores surgidos en los ochenta, tampoco dramatiza, simplemente los 'coloca' en su existencia real. El cine de Kieslowski nos ayuda a entendernos a nosotros mismos; es una llamada de atención a nuestras conciencias...

¿Que queda entonces tras esta trama mecanizada y perfecta en la que vivimos? Sólo queda el azar. Kieslowski deja la puerta del azar abierta como salvación, gracias a ella se puede decir que todavía es posible amar, sentir, vivir... Así el azar, ya sea en 
aspectos fundamentales como a veces en los anecdóticos, es la segunda característica del cine de estos dos polacos - la primera era como hemos visto la perfección, la precisión -. El azar es la base de La doble vida de Verónica 1990; por azar coinciden en el mismo barco, que naufraga al final de Rojo, todos los protagonistas de la Trilogía; por azar la misma señora tira la botella para reciclar en las tres películas de la Trilogía; un perro que se escapa y es atropellado hace que se encuentren el dueño y la protagonista en Rojo; una mujer madura que vive frente a un adolescente en No amarás, etc. Porque el azar rompe la perfección y la predecibilidad, y al mismo tiempo liga las vidas de unos con otros con mayor o menor consistencia (en Rojo, la protagonista y su vecino). En la sólida estructura de sus películas -gracias a los guiones de Pisiewick, trabada visualmente con los colores en la Trilogía - al final todo depende del azar - magistralmente insertado en la narración -; porque las películas de Kieslowski aparentemente se basan en la solidez de lo perfecto pero en realidad se sustentan en la fragilidad de lo circunstancial: el perro que escapa, el barco que naufraga, la vecina... Y eso es lo que las hace vivas y creíbles, cercanas a nosotros. Aunque parezca lo contrario, nada está decidido de antemano, el futuro es imprevisible y, por tanto, esperanzador. (El adolescente de No amarás hará comprender a la mujer que, a pesar de todo, todavía existe la posibilidad de amar de otro modo.)

Kieslowski y Pisiewick fueron de los pocos cineastas con verdadera calidad surgidos en aquellos años y que entendieron la posmodernidad como nadie, que supieron mantenerse al margen de los fuegos artificiales imperantes (entonces y ahora), demostrando su fuerte personalidad, y que, afortunadamente, no fueron marginados de los festivales y de los medios de comunicación - y por tanto no vetados al común espectador-. Así Kieslowski, cuando un crítico le preguntó en una de las últimas entrevistas que concedió, cómo se sentía en el desolador panorama del cine de ese momento - hace solo unos años -, respondió que era como "hacer una travesía del desierto en solitario". Kieslowski se sentía solo intelectual y artísticamente, como 
tantos de sus personajes, y fue uno de los últimos en dejar testimonio de lo que el cine puede llegar a ser. 